\title{
Which Are the Factors Associated to Child Mistreatment? Use of a Routinely Collected Specific Dataset for Surveillance in a Belgian Pediatric Unit
}

\author{
Christelle Senterre $^{1^{*}}$, Brigitte Vanthournout ${ }^{2}$ \\ ${ }^{1}$ Research Centre of Epidemiology, Biostatistics and Clinical Research, School of Public Health, Université Libre \\ de Bruxelles, Brussels, Belgium \\ ${ }^{2}$ SOS enfants ULB, CHU Saint Pierre Hospital, Brussels, Belgium \\ Email: ${ }^{*}$ Christelle.Senterre@ulb.ac.be
}

Received 30 April 2014; revised 2 June 2014; accepted 9 June 2014

Copyright (C) 2014 by authors and Scientific Research Publishing Inc.

This work is licensed under the Creative Commons Attribution International License (CC BY).

http://creativecommons.org/licenses/by/4.0/

c) (i) Open Access

\begin{abstract}
Introduction: Child abuse is a serious health problem with compelling evidence that the phenomenon is common throughout the world. The Center "SOS enfants ULB" is a specialized team, established in a pediatric ward, which had mission to prevent and to treat the situations of children victims of physical, sexual, psychological abuse or of neglect. Our objectives were to describe the characteristics of $\mathbf{4 3 9}$ children hospitalized for (suspicion of) maltreatment and to investigate different factors potentially associated with the children at risk of neglect or maltreatment, the children victims of neglect and the physically maltreated children. Methods: Chi square test and multinomial logistic regression models with clustered robust standard error were applied to assess the relationship between the three types of mistreatment and the potential associated factors. Results: Maltreatment was observed for almost one in two children (48.7\%) and approximately four on ten $(41.5 \%)$ were considered at risk. Physical abuse was the most prevalent $(57.9 \%)$ among the maltreated children and neglect was the second most prevalent $(37.4 \%)$ form of maltreatment. Regarding the criteria leading to hospitalisation, at least one protective criterion was observed for a little more than eight children on ten. The parental criteria have shown that social problems and conjugal conflicts were the most prevalent for this category of hospitalisation criteria. Conclusion: These data, concerning the hospitalized children for which there is (suspicion of) mistreatment, collected by this team make important contribution to describing child maltreatment and its associated factors. Despite the fact that these hospitalized cases may be probably more serious than those who were not reported, every event, however small it may be, should be known for better organizing each level of prevention.
\end{abstract}

*Corresponding author.

How to cite this paper: Senterre, C. and Vanthournout, B. (2014) Which Are the Factors Associated to Child Mistreatment? Use of a Routinely Collected Specific Dataset for Surveillance in a Belgian Pediatric Unit. Health, 6, 1396-1407. 


\title{
Keywords
}

\section{Child Maltreatment, Physical Abuse, Neglect, Epidemiology, Surveillance}

\section{Introduction}

\author{
"Every child has the right to health and a life free from violence" [1]
}

According to the World Health Organization [2] in its world report on violence and health, child abuse is a serious health problem with compelling evidence that the phenomenon is common throughout the world. Always in this report, a definition, based on the WHO Consultation on Child Abuse Prevention, is proposed. This definition is "child abuse or maltreatment constitutes all forms of physical and/or emotional ill-treatment, sexual abuse, neglect or negligent treatment or commercial or other exploitation, resulting in actual or potential harm to the child's health, survival, development or dignity in the context of a relationship of responsibility, trust or power" [2]. Therefore, four forms of maltreatment are widely recognized; it is a question of physical abuse, sexual abuse, psychological abuse (sometimes referred to as emotional abuse) and neglect [3][7]. All these forms of mistreatment can have consequences that can include impaired physical and mental health throughout life, and adverse social and occupational effects that carry a heavy economic and social burden [8].

How many children are maltreated in the population is a subject of debate in literature. There is an agreement only that the true extent of child maltreatment is unknown and estimates indicate that between half to four fifths of all victims of mistreatment are not known to child protection services [9]. The frequency of child maltreatment is challenging to estimate because of, in some cases, variation in definitions, but also and particularly, the type of maltreatment being studied, and the comprehensiveness and quality of official statistics and of surveys [8]. Lack of good data on the extent, of the associated factors and on the consequences of mistreatments could hold back the development of appropriate responses. Without good data it is difficult to develop a proper awareness of child abuse and neglect and expertise in addressing the problem within the health care, legal and social service professions [2] [10] [11].

In Belgium, as explained by AlEissa [12] and colleagues, there is no national data collection program because, despite the fact that each community (the Flemish, the Wallonian and the German community) has, in its competences, the educational matters as well as the cultural and individual matters; the Belgian Federal Government stays responsible for health care and justice. So, both regional and federal policy makers have responsibility for child maltreatment. Situation makes harder the coordination of all social services and magistrates who are considering and dealing with alleged maltreatment.

For the French speaking region, the "Office de la Naissance et de l'Enfance" (ONE is its acronym and, in English, it will be called "Office of the Birth and Childhood") has in its missions, the prevention and the comprehensive care of the children maltreatment. In this setting, two legal texts (a Decree of 12 May 2004 on assistance to victims of child abuse and its implementing order) recognize the existence of 14 special teams. The ONE subsidizes and oversees their work. These teams, equitably distributed on the territory, have missions to prevent and to treat the situations of children victims of physical, sexual, psychological abuse or of neglect. The Center "SOS enfants ULB" (in English it will be called "SOS children") from the Free University of Brussels (ULB is its acronym in French) was created in 1985 and is one of these 14 teams existing in the French Community of Belgium. The Center "SOS enfants ULB" has the particularity to be established within the Academic Hospital Center named "CHU Saint Pierre". Located in the heart of Brussels, it is a public and general hospital with a real social vocation. Among this Center "SOS enfants ULB", there is a specific team which is in a close link with the pediatric ward. This team is coordinated by one child psychiatrist and is constituted with 2 psychologists, 2 social assistants, 1 psychomotor therapist and 1 pediatrician. Since 2007, this team had chosen to systemize and to synthetize the data, collected during the children stays, through a computerized tool.

The objectives of this study were, therefore, to describe the characteristics of all the hospitalized children for (suspicion of) maltreatment and to investigate different factors potentially associated with the children at risk of neglect or maltreatment, the children victims of neglect and the maltreated children. 


\section{Methodology}

\subsection{Data Source}

Between 2007 and 2012, 504 children were been hospitalized; with a yearly number almost steady $\left(\mathrm{n}_{2007}=91\right.$, $\mathrm{n}_{2008}=73 ; \mathrm{n}_{2009}=85, \mathrm{n}_{2010}=79, \mathrm{n}_{2011}=90$ and $\mathrm{n}_{2012}=86$ ). Over time, the situations encountered can be quite complex. Several situations can be observed, leading to several specific groups for the analysis: the first situation concerns the children, hospitalized alone (without siblings) one time during the investigated period. The members of this group are independent of each other. The second situation concerns the siblings hospitalized one time during the studied period. The members of this group are not independent of one another for some variables (e.g. the information relative to the parents). Another situation concerns the children (alone or in siblings) hospitalized more than one time during the studied period. In this group, information on the next hospital stay are linked to the first stay. Finally, the last situation is the more complex situations. These complicated situations were, for example, a child hospitalized alone the first time and who came back several months later with a member of his siblings. The inverse situation was also met: the first hospitalisation was related to a siblings and the re-hospitalisation was only related to one of the siblings member. Another example was the situation where two members of a same siblings were hospitalized but not at the same time. Among the 504 hospitalized children, 286 (56.7\%) were in the group "hospitalized alone and only one time"; 153 (30.4\%) were in the group "siblings hospitalized one time"; 48 (9.5\%) were in the group "hospitalized more than one time" and finally 14 (3.4\%) children were in the group of "complicated situations". In this paper we have made the choice to only take into account the children hospitalized only one time (we have not taken into consideration the children with re-admissions) regardless of the fact that there were hospitalized alone or in siblings. So, the number of children is equal to 439 (with $\mathrm{n}_{2007}=69, \mathrm{n}_{2008}=59 ; \mathrm{n}_{2009}=72, \mathrm{n}_{2010}=71, \mathrm{n}_{2011}=89$ and $\mathrm{n}_{2012}=79$ ) with 153 children hospitalized in siblings (with $\mathrm{n}_{2007}=26, \mathrm{n}_{2008}=21 ; \mathrm{n}_{2009}=28, \mathrm{n}_{2010}=28, \mathrm{n}_{2011}=24$ and $\mathrm{n}_{2012}=26$ ). These siblings were distributed according to 50 siblings of 2 children, 9 siblings of 3 children, 5 siblings of 4 children and finally 1 siblings of 6 children. Overall, data are presented without taking into account the notion of siblings. However, the parental criteria like hospitalisation criteria were presented separately of the other hospitalisation criteria because the parents of siblings are normally the same and consequently, not taking into account the siblings notion would give an overestimation of the proportions of these criteria. So, the results presented in the Table 2 was related to a number of situations $(n=351)$ but not to a number of children $(n=439)$.

\subsection{Recorded Data}

Upon arrival and throughout the stay, a series of information are collected about the children and their situations. These information concern some socio-demographic characteristics (age, gender, living environment before the hospitalisation). If the child was hospitalized with siblings it was marked (note that each member of the siblings has his own record in the dataset resulting from the encoding in the computerized tool). Some information about known previous case files were also reported. These previous files could be (or not) files opened previously by the SOS enfants ULB team, by Youth Services or by a Juvenile Judge (but, as a reminder, in this paper, there are no children who were hospitalized before). Due to the social vocation of the hospital and the fact that it is located in Brussels, the team encounters sometimes language barrier with the children and their relatives. So, the intervention of a translator was also reported. Concerning the factors taken on a share of hospitalisations, four types were reported: they concern medical and psychiatric aspects of the children but also parental factors and especially the potential protective factors implicated. During the stay, the mistreatment checkup is done and a personality diagnosis is established. Finally, at the discharge, the return (or not) in the living environment and the possible measures taken were also reported (Figure 1).

All the collected information was not used in this paper, so we present the retained variables (main outcomes investigated and associated factors) just below.

\subsection{Main Outcomes}

Based on the observations and the assessments of the team, the first question is to clarify if there is (unmistakably) "child maltreatment", if the child is "at (high) risk" of mistreatment or neither of these two possibilities. The three categories of this first outcome are mutually exclusive. Note that for a small number of cases, the team concludes that there is no abuse and that the child is also not at risk. If there is child maltreatment, four non- 


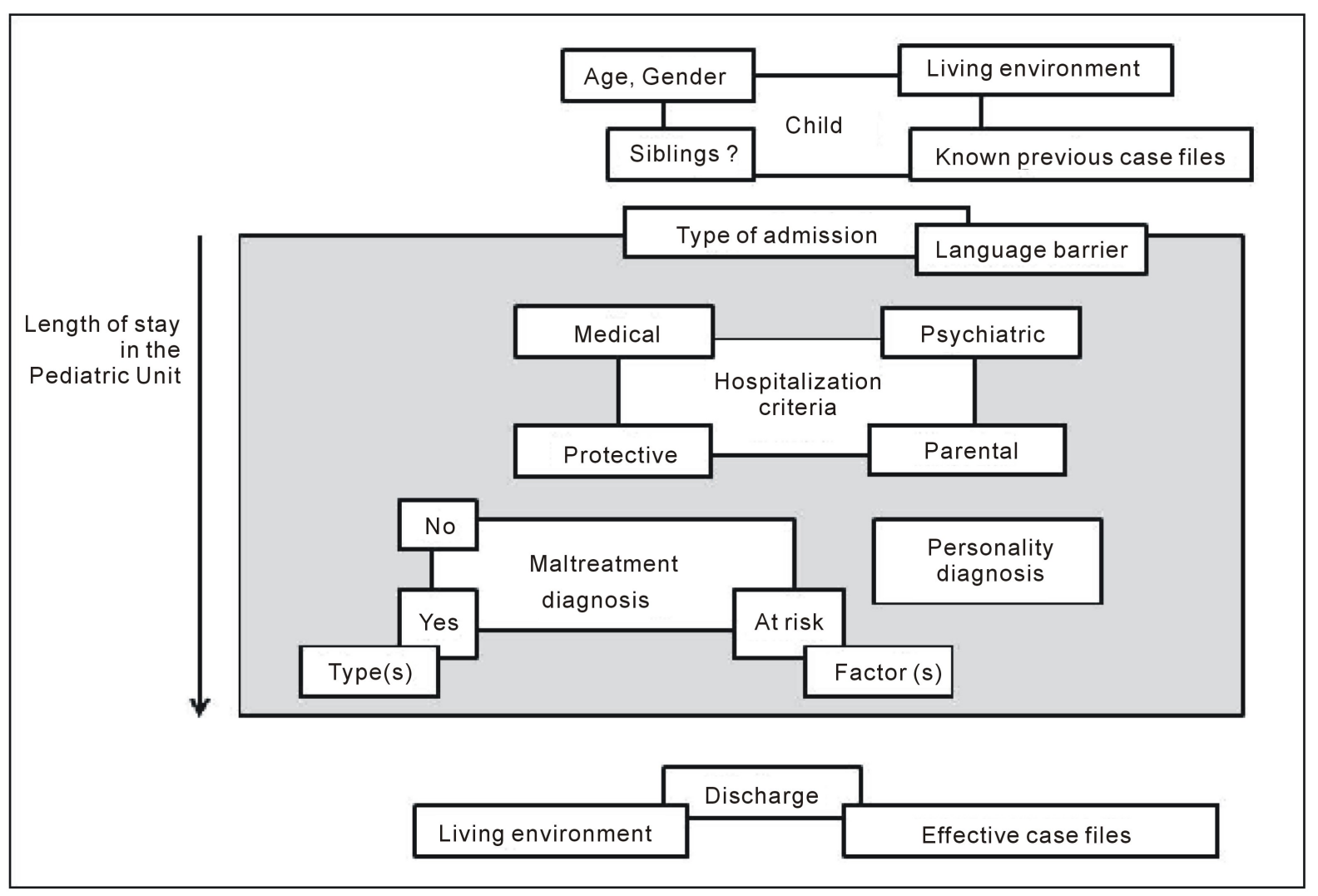

Figure 1. Recorded variables from the admission to the discharge of the child.

mutually exclusive forms of maltreatment can be reported. These forms are the "physical abuse", the "sexual abuse", the "neglect" and the "mental and psychological cruelty". Some specifications are reported for the physical and sexual abuses. For the physical abuse, are reported the four next non-mutually exclusive categories: the "hitting/biting/pinching/scratching" category, the "shaken baby syndrome/shaking/throwing" category, the "strangulation (attempt)/suffocation (attempt)" category and the "torture/burn/administration of dangerous substances" category. For the sexual abuse, there are three non-mutually exclusive categories reported. It is the "indecent behavior" category, the "touching behavior" category and the "penetration" category. Finally, several non-mutually exclusive items could be reported for the children "at risk". There are the "psychiatric parents", the "alcoholic and/or drug addicted parents", the "social issue" or the "conjugal conflict".

Based on the explained variables above, we have constructed, to study the associations with potential associated factors, a new variable in three mutually exclusive levels corresponding to be a child "at risk", a "neglect" child or a "physically maltreated" child.

\subsection{Associated Factors}

The socio-demographic factors investigated were age, gender, the country of birth of the children and their life environment before the hospitalisation. This life environment could be the family, an institution, but also and especially for the new-born babies, a neonatal center or a maternity ward. Were also reported the known previous case files. These files can correspond to mistreatment history known by a Health Youth Service or by Juvenile Judge and/or Court. The type of admission at the hospital could be of two types: on one hand it could be a planned admission or one the other hand an emergency admission. If it was an emergency admission, the children could be led by parents or by close relatives but also by the Police or the medical service "100" (the "100" is the emergency number to call in Belgium). Regarding the administrative aspects of the admission, month of year and day of week were studied. The necessity of a translator, for facilitate the communication with the children and/or parents, was also investigated. Finally, the length of stay, corresponding to the number of day between the admission and the discharge was calculated. 


\subsection{Statistical Analyses}

Proportions were used for describe on one hand both the characteristics of the children and their hospitalisation criteria and on the other hand the types of mistreatment encountered. The variations of proportions of each potential associated factor were reported in the three studied levels of child status ("child at risk", "neglected child" and "physically maltreated child"). The relationship was assessed using the Pearson's Chi-square test. Results were considered statistically significant when $\mathrm{p}<0.05$. To estimate the strengths of the associations, odds ratios (OR) with their $95 \%$ confidence intervals $(95 \% \mathrm{CI})$ were computed by the way of a simple multinomial logistic regression with clustered robust standard error (the robust standard error was chosen for taking into account the siblings effect). To further assess these relationships but also for taking into account the potentials confounding effects of some variables, a multinomial logistic regression model (also with clustered robust standard error) was applied, with the "at risk" level as the reference. Adjusted odds ratios, derived from the model, were presented with their 95\% confidence intervals and the p-value of the Wald's test. To assess the fit of the model, we used the generalized Hosmer and Lemeshow goodness-of-fit [13].

\section{Results}

Figure 2 shows that there was not a large change in the number of children hospitalized according to the month of the year. The monthly mean is equal to 37 children (Data not shown). The analysis by weekdays shows that there were fewer admissions during the weekend (Figure 3).

\subsection{Characteristics of the Children, of Their Hospital Stay and of Their Hospitalisation Criteria}

Table 1 shows a gender ratio nearly equal to one (girls/boys $=1.03$ ) and almost half of the children $(48.3)$ have less than or equal 3 years. A large part of the admissions occurred in emergency (81.6\%) with the children led by the Police or the medical service "100". In practice, a translator was required for one in five cases. The most encountered languages were the Arabic languages, the languages of the Eastern countries and the African dialects. To a lesser extent, some languages from the West countries were also encountered (Data not shown). For $43.5 \%$ of the children, there were known previous case files. The majority of these files were located at the Health Youth Service or at the Juvenile Judge and/or Court (Data not shown).

Regarding the criteria leading to hospitalisation, at least one protective criterion was observed for a little more than eight children on ten. The suspicions of mistreatment such as physical abuse or neglect were the major criteria encountered ( $25.3 \%$ and $19.8 \%$ respectively). It was also observed that an obvious physical abuse was reported for $15.5 \%$ of the children. A little less than a quarter $(23.7 \%)$ of the children presented at least one medical criterion (with $10.5 \%$ of medical pathology) and a little more than one-tenth $(12.1 \%)$ presented at least one psychiatric criterion (Figure 4). These three groups of criteria being not mutually exclusive, a child could have more than one. Hence, we have observed $34.2 \%$ of children with two or more criteria (with $27.1 \%$ with 2 criteria; $4.1 \%$ with 3 and $3.0 \%$ with 4 criteria) (Data not shown).

The parental criteria have shown that social problems and conjugal conflicts were the most prevalent for this category of hospitalisation criteria. It was also observed a non-negligible number of situations with psychiatric problems for the mother or with violent or aggressive behavior for the father (Table 2). As for the three others types of criteria, these ones were not mutually exclusive. Hence, we have observed $28.5 \%$ situations in which there were 3 criteria or more with a maximum of 7 observed (Data not shown).

\subsection{About the Mistreatment Observed}

Maltreatment was observed for almost one in two children (48.7\%) and approximately four on ten (41.5\%) were considered at risk. Physical abuse was the most prevalent (57.9\%) among the maltreated children, with the hitting/biting / pinching/scratching as the major expression of these abuses. Neglect was the second most prevalent (37.4\%) form of maltreatment (Figure 5). For 42 (19.6\%) children on the 214 who were maltreated, several forms of maltreatment were reported: 17 children suffered from neglect and physical abuse, 12 from cruelty and physical abuse, 7 have had both physical and sexual abuses; 4 children were subjected to neglect and to cruelty, one to neglect and to sexual abuse; and finally, one child had endured physical and sexual abuses associated with cruelty (Data not shown). Regarding the sexual abuse, penetration and touching behavior were the most 


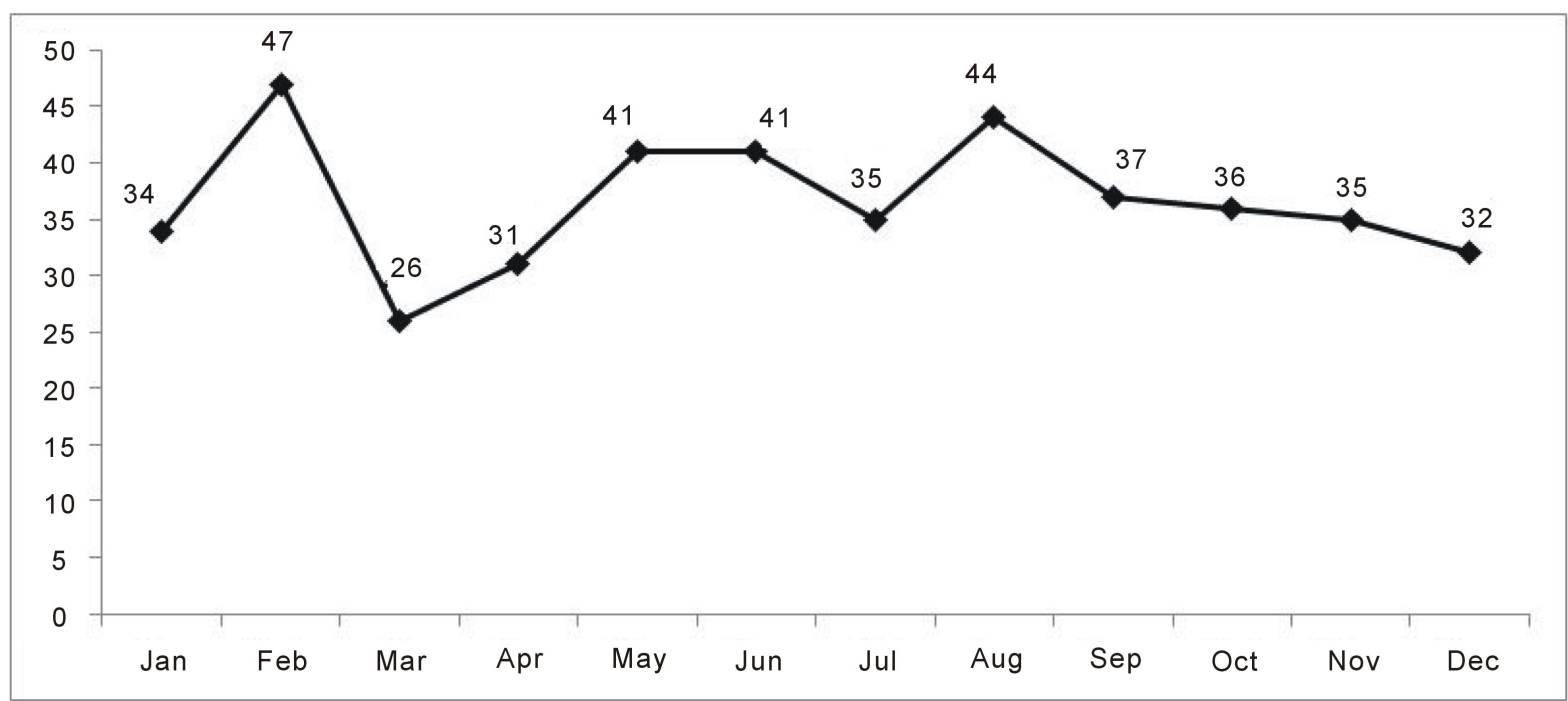

Figure 2. Number of children hospitalised according to the months of the year.

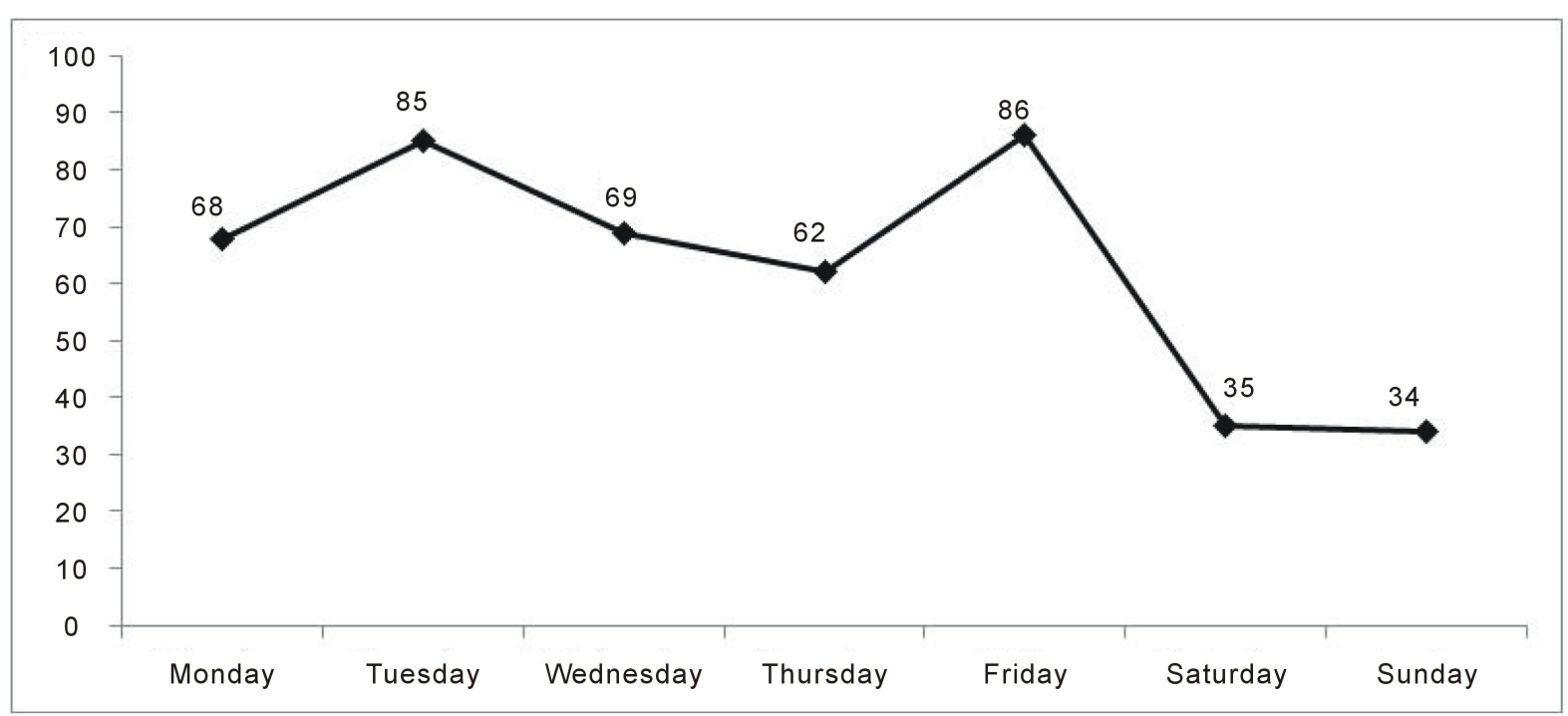

Figure 3. Number of children hospitalised according to the months of the weekedays.

prevalent forms (61.3\% and 41.9\% respectively) of this type of mistreatment (Figure 5).

\subsection{Associations between Some Specific Mistreatment and the "Child at Risk", "Neglected Child" and "Physically Maltreated Child" Status}

Table 3 shows that there were statistically significant variations for the proportions of age, country of birth, living environment, existence of previous case files and type of admission at the hospital according to the three forms of mistreatment investigated. On the contrary, there was no significant difference for gender and length of stays. Actually, the younger children ( $\leq 3$ years) were less represented in the "physically maltreatment" group (24.3\%) and in the "neglect" (55.5\%) group than in the "at risk" group (62.7\%). There were more children who were not born in Belgium in the "maltreatment" group than in the two others (38.3\% vs. 13.2\% for the "at risk" group and $11.1 \%$ in the "neglect" group). Regarding the known previous case files, the proportion was the higher in the "neglect" group (61.9\% vs. 46.2\% and 33.6\% in the "at risk" and "maltreatment" groups respectively). Finally, admission was more frequently an emergency situation for the "“neglect” and the "physically maltreatment” groups than for the “at risk” group (87.3\% and 86.0\% respectively vs. 75.3\%). 


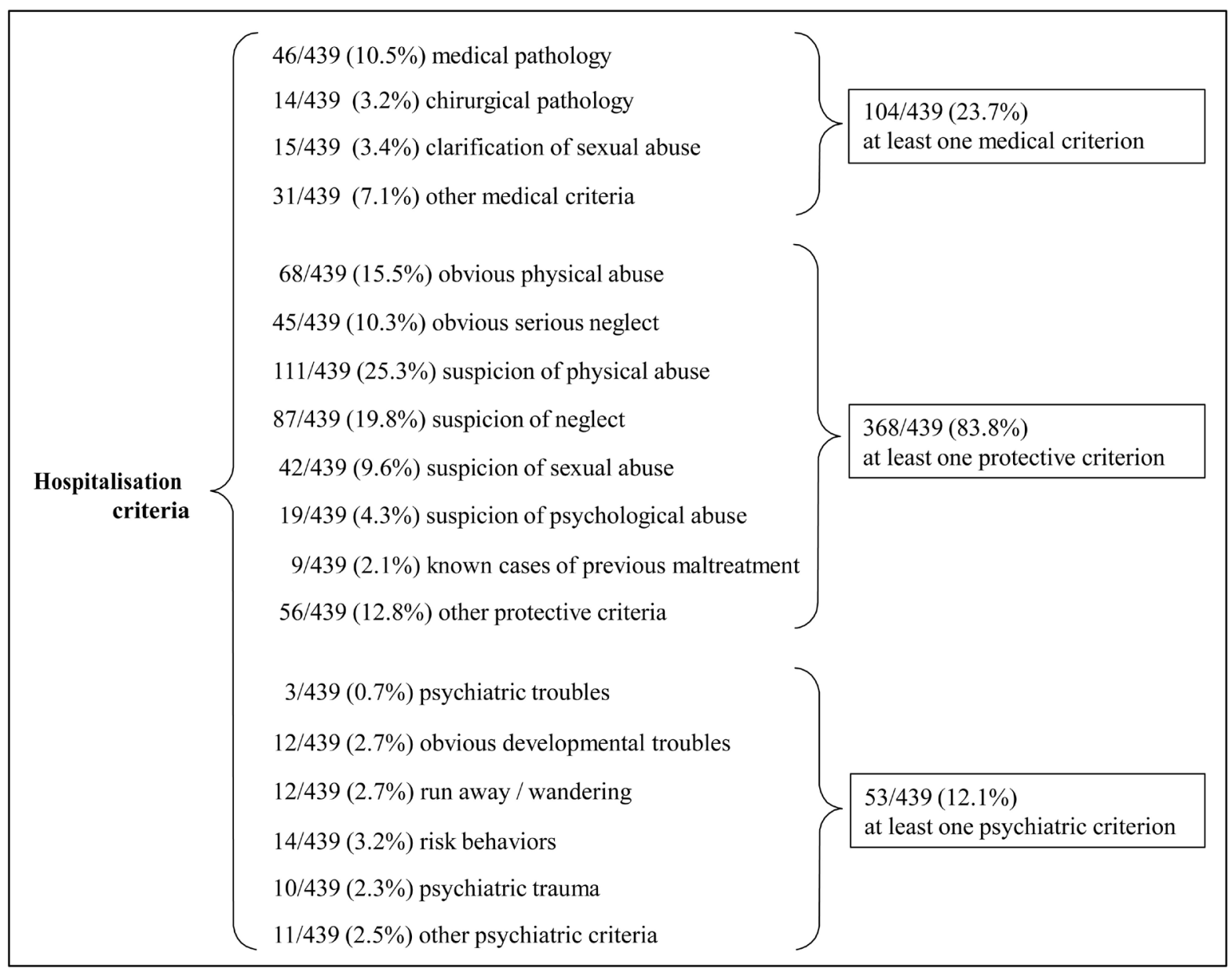

Figure 4. Description of the medical, protective and psychiatric hospitalisation criteria of the children.

After adjusting for all the independent variables present in the multivariate model, the association between age and type of mistreatment was noticeably weaker than the one observed in univariate analyses, especially for the maltreatment association. It was the same tendency for the country of birth. Eventually, in this model, the association with the type of admission did not remained statistically significant (Table 4).

\section{Discussion}

In our study, we have investigated the variations of some potential associated factors with the status of be "at risk", "neglected" or "physically maltreated". At the best of our knowledge, this notion of being at risk has not been much studied as well as the neglect, because these two mistreatment forms were not really easy to estimate [14]. As reported by Gilbert [6] and colleagues, the measurement of neglect in the community is difficult, partly because there are many aspects of omission or lack of provision of care that are harmful or could place a child at risk of harm. The widely recognized forms of mistreatment were habitually physical abuse, sexual abuse, psychological abuse and neglect.

Our results show that the numbers of children maltreated on one hand, and at risk of mistreatment, on the other hand, were nearly equal (214 and 182 children respectively). Afterwards, between the several four forms of mistreatment investigated, the most observed form was first the physical abuse (57.9\%), followed after by the neglect (37.4\%), the sexual abuse (14.5\%) and finally the mental and psychological cruelty (10.3\%). These results were not really in agreement with the too rare literature which reported that neglect was the most prevalent form of child maltreatment [1] [6] [7] [15]. This difference could possibly be explained by the fact that the children, considered in this study, were hospitalized children. Despite the fact that neglect could also have serious psychological damages for the children, this form of mistreatment doesn't lead directly to hospitalisation; 
Table 1. Description of the characteristics of the children and of their hospital stays.

\begin{tabular}{|c|c|}
\hline & n (\%) \\
\hline \multicolumn{2}{|l|}{ Gender } \\
\hline Boys & $216(49.2)$ \\
\hline Girls & $223(50.8)$ \\
\hline \multicolumn{2}{|l|}{ Age (years) } \\
\hline$\leq 3$ & 212 (48.3) \\
\hline $4-11$ & 138 (31.4) \\
\hline$\geq 12$ & 89 (20.3) \\
\hline \multicolumn{2}{|l|}{ Born in Belgium } \\
\hline No & $91(20.7)$ \\
\hline \multicolumn{2}{|l|}{ Needs of a translator } \\
\hline Yes & $88(20.1)$ \\
\hline \multicolumn{2}{|l|}{ Living environment } \\
\hline Family & $396(90.2)$ \\
\hline Other & $43(9.8)$ \\
\hline \multicolumn{2}{|l|}{ Admission } \\
\hline Emergency & $358(81.6)$ \\
\hline Planned or transfer & $81(18.4)$ \\
\hline \multicolumn{2}{|l|}{ If emergency admission, led by } \\
\hline Parents & $80(22.4)$ \\
\hline Police or medical service (“100”) & $237(66.2)$ \\
\hline Other & $41(11.4)$ \\
\hline \multicolumn{2}{|l|}{ Knownprevious case files } \\
\hline Yes & $191(43.5)$ \\
\hline \multicolumn{2}{|l|}{ Length of stay (days) } \\
\hline$<7$ & $126(28.7)$ \\
\hline $7-14$ & $102(23.2)$ \\
\hline $14-30$ & 104 (23.7) \\
\hline$\geq 30$ & $107(24.4)$ \\
\hline
\end{tabular}

Table 2. Description of the parental criteria of hospitalisation.

\begin{tabular}{|c|c|c|}
\hline$(\mathrm{n}=351)^{\mathrm{a}}$ & Mother & Father \\
\hline Pregnancy & $8(2.3 \%)$ & * \\
\hline Hospitalisation & $7(2.0 \%)$ & $0(0.0 \%)$ \\
\hline Psychiatricproblematic & $63(17.9 \%)$ & $13(3.7 \%)$ \\
\hline Acute poisoning & 37 (10.5\%) & $11(3.1 \%)$ \\
\hline Social problems & $81(23.1 \%)$ & $36(10.3 \%)$ \\
\hline Death & $8(2.3 \%)$ & $5(1.4 \%)$ \\
\hline Conjugal conflict & $83(23.6 \%)$ & $57(16.2 \%)$ \\
\hline Violent/aggressive & $36(10.3 \%)$ & 59 (16.8\%) \\
\hline Other parental criteria & $66(18.8 \%)$ & $34(9.7 \%)$ \\
\hline
\end{tabular}

${ }^{\mathrm{a}} \mathrm{n}$ is equal to 351 , corresponding to the number of situations and not equal to 439 ( $\mathrm{n}$ of children) because some children have the same parents (due to the siblings).

so this form of mistreatment is probably underestimated in our case. To support this hypothesis, we refer to the study of Keshavarz [16] done in a pediatric emergency department which also found more physical abuse compared to neglect. Another hypothesis could be found in the fact that we have an "at risk" category of children. As says above, this category of "mistreatment" is not classically investigated in the literature, so it is possible that some of these children could be judged as neglected child by other researchers. Concerning the 182 children 


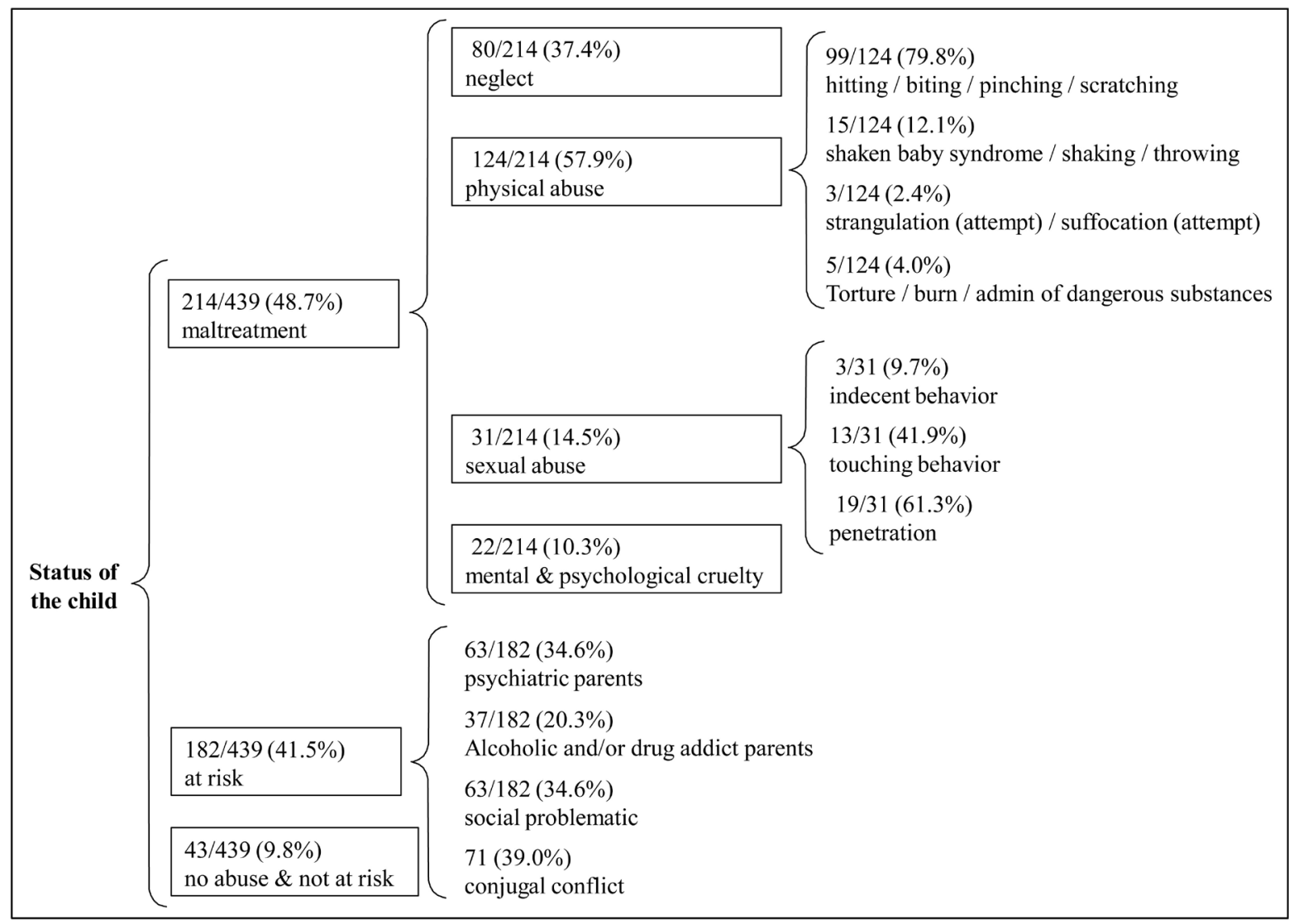

Figure 5. Description of the child's status and of the several forms of each types of mistreatment.

at risk, the question could be asked why these children were admitted to hospital. The CHU Saint Pierre is known as a hospital with social vocation, with a special team which takes in charge the mistreated children. Hence, it is more "easier" for a person, who suspects a case of neglect or mistreatment on a child, to bring this child to an emergency ward than to bring him to a police station or to a Judge.

Regarding the factors having led to the hospitalisation, protective factors were the most frequently observed (83.8\%). The suspicion of physical abuse and the suspicion of neglect were the most prevalent (25.3\% and 19.8\% respectively) but for a non-negligible number of situations, we were beyond the suspicion, with an obvious manifestation of physical abuse (15.5\%) or of serious neglect (10.3\%).

For the children at risk, the investigated factors were all parental factors. Among them, the conjugal conflict was the most observed (39.0\%). This factor is well reported in the literature as a risk factor of several forms of mistreatment, as well as mental health problems and parental substance use [6] [15]-[18]. These two others parental factors have also been observed (34.6\% and 20.3\% respectively).

Regarding the results between the variations of some associated factors and the status of be "at risk", "neglected" or "physically maltreated", we have observed that the children at risk or neglected were significantly younger than those in the physically maltreated group. These observations are in agreement with the literature which postulates that neglect could be related to the parent's inability to cope with the demands of the baby or the little child and that the maltreatment could be related to the notion of discipline and punishment [1] [15].

Looking at the country of birth, the proportion of children who were not born in Belgium was higher in the physically maltreated group (38.3\%) than in the neglect group (11.1\%) or in the at risk group (13.2\%). One of the explanations could be that the children in this group were older than those in the "at risk" or in the "neglect" groups (for the younger, the probability of being born in Belgium is higher-this is as an example the case of the babies born at the hospital). Nevertheless, after adjustment for age (through the multivariate model), the difference remains significant. As well as it was done in literature, the cultural hypothesis could be therefore proposed [1] [2] [18]. But it is also important to reminder the real social vocation of the CHU Saint Pierre. This hospital 
Table 3. Variations of the proportions of the associated factors according to the "child at risk", the "neglect child" and the "physical maltreated child” status.

\begin{tabular}{|c|c|c|c|c|c|c|}
\hline & At risk & Neglect & $\begin{array}{c}\text { Neglect } \\
\text { vs. At risk }\end{array}$ & Maltreatment & $\begin{array}{c}\text { Maltreatment } \\
\text { vs. At risk }\end{array}$ & \\
\hline & n (\%) & n (\%) & $\begin{array}{c}\text { OR } \\
(95 \% \mathrm{CI})\end{array}$ & n (\%) & $\begin{array}{c}\text { OR } \\
(95 \% \mathrm{CI})\end{array}$ & p value \\
\hline Gender & $(n=182)$ & $(n=63)$ & & $(n=107)$ & & \multirow{3}{*}{0.301} \\
\hline Boys & $86(47.3)$ & $36(57.1)$ & 1.0 & $58(54.2)$ & 1.0 & \\
\hline Girls & $96(52.7)$ & 27 (42.9) & $0.67(0.39-1.17)$ & $49(45.8)$ & $0.76(0.46-1.24)$ & \\
\hline Age (years) & $(n=182)$ & $(n=63)$ & & $(n=107)$ & & \multirow{4}{*}{$<0.001$} \\
\hline$\leq 3$ & 114 (62.7) & $35(55.5)$ & 1.0 & $26(24.3)$ & 1.0 & \\
\hline $4-11$ & 43 (23.6) & $25(39.7)$ & 1.89 (0.97 - 3.69) & 42 (39.3) & 4.28 (2.34 - 7.82) & \\
\hline$\geq 12$ & $25(13.7)$ & $3(4.8)$ & $0.39(0.11-1.40)$ & $39(36.4)$ & $6.84(3.46-13.51)$ & \\
\hline Born in Belgium & $(n=182)$ & $(n=63)$ & & $(n=107)$ & & \multirow{3}{*}{$<0.001$} \\
\hline Yes & 158 (86.8) & $56(88.9)$ & 1.0 & $66(61.7)$ & 1.0 & \\
\hline No & $24(13.2)$ & $7(11.1)$ & $0.82(0.26-2.60)$ & $41(38.3)$ & $4.09(2.20-7.59)$ & \\
\hline Living environment & $(n=182)$ & $(n=63)$ & & $(n=107)$ & & \multirow{3}{*}{0.009} \\
\hline Family & $154(84.6)$ & $57(90.5)$ & 1.0 & 105 (98.1) & 1.0 & \\
\hline Other & $28(15.4)$ & $6(9.5)$ & $0.58(0.17-2.03)$ & $2(1.9)$ & $0.10(0.02-0.45)$ & \\
\hline Admission & $(n=182)$ & $(n=63)$ & & $(n=107)$ & & \multirow{3}{*}{0.040} \\
\hline Emergency & 137 (75.3) & 55 (87.3) & 1.0 & $92(86.0)$ & 1.0 & \\
\hline Planned or transfer & $45(24.7)$ & $8(12.7)$ & $0.44(0.19-1.02)$ & $15(14.0)$ & $0.50(0.26-0.96)$ & \\
\hline If emergency admission, led by & $(n=137)$ & $(n=55)$ & & $(\mathrm{n}=92)$ & & \multirow{4}{*}{0.003} \\
\hline Parents & $35(25.6)$ & $6(10.9)$ & 1.0 & $16(17.4)$ & 1.0 & \\
\hline Police or medical service (“100”) & $91(66.4)$ & $45(81.8)$ & $2.88(1.07-7.80)$ & $54(58.7)$ & $1.30(0.60-2.79)$ & \\
\hline Other & $11(8.0)$ & $4(7.3)$ & $2.12(0.47-9.62)$ & $22(23.9)$ & $4.38(1.57-12.16)$ & \\
\hline Knownprevious case files & $(n=182)$ & $(n=63)$ & & $(n=107)$ & & \multirow{3}{*}{0.007} \\
\hline Yes & $98(53.8)$ & $24(38.1)$ & 1.0 & $71(66.4)$ & 1.0 & \\
\hline No & $84(46.2)$ & 39 (61.9) & $1.90(0.95-3.77)$ & $36(33.6)$ & $0.59(0.34-1.02)$ & \\
\hline Length of stay (days) & $(\mathrm{n}=182)$ & $(n=63)$ & & $(n=107)$ & & \multirow{5}{*}{0.536} \\
\hline$<7$ & $49(26.9)$ & $12(19.1)$ & 1.0 & 35 (32.7) & 1.0 & \\
\hline $7-14$ & $40(22.0)$ & $14(22.2)$ & $1.43(0.56-3.64)$ & $25(23.4)$ & $0.88(0.42-1.81)$ & \\
\hline $14-30$ & 49 (26.9) & $15(23.8)$ & $1.25(0.48-3.28)$ & $22(20.5)$ & $0.63(0.30-1.33)$ & \\
\hline$\geq 30$ & $44(24.2)$ & $22(34.9)$ & $2.04(0.82-5.07)$ & $25(23.4)$ & $0.80(0.38-1.68)$ & \\
\hline
\end{tabular}

welcomes people in a position of vulnerability; some families are in Belgium, living in poor socio-economic conditions, after having run away their countries due to suffered violence (e.g. wars); then, as stated by Barudy and colleagues [19], in these families in exile, who have suffered from traumas, some family dysfunctions may occur within the family and therefore, these traumas could be an exacerbating risk factor of child maltreatment.

\section{Conclusion}

These data, concerning the hospitalized children for which there is (suspicion of) mistreatment, collected by this team make important contributions to describing child maltreatment and its associated factors. But, as written by Fallon [9] and colleagues, the tip-of-the-iceberg analogy comes to mind when one thinks on the results presented here. On one hand, because, it is well known that a large proportion of child maltreatment is never reported to child protection and law enforcement authorities but on the other hand, because, we only here have the hospitalized cases. Despite the fact that these cases may be probably more serious than those who were not reported, every event, however small it may be, should be known for better organizing the primary and the secondary 
Table 4. Adjusted odds ratios (CI95\%) of the associated factors according to the "child at risk", the "neglect child" and the "physical maltreated child” status.

\begin{tabular}{|c|c|c|c|}
\hline \multirow{2}{*}{$\begin{array}{c}(\mathrm{n}=352 \text { with } 182 \text { at risk, } 63 \text { neglect and } \\
107 \text { maltreatment, } \mathrm{pH} \& \mathrm{~L}=0.632)\end{array}$} & \multicolumn{3}{|c|}{$\begin{array}{l}\text { Maltreatment } \\
\text { vs. At risk }\end{array}$} \\
\hline & $\begin{array}{c}\text { OR }_{\mathrm{a}} \\
(95 \% \mathrm{CI})\end{array}$ & $\begin{array}{c}\mathrm{OR}_{\mathrm{a}} \\
(95 \% \mathrm{CI})\end{array}$ & $p$ value \\
\hline $\begin{array}{c}\text { Gender } \\
\text { Boys } \\
\text { Girls }\end{array}$ & $\begin{array}{c}1.0 \\
0.72(0.40-1.30)\end{array}$ & $\begin{array}{c}1.0 \\
0.67(0.39-1.15)\end{array}$ & 0.301 \\
\hline $\begin{array}{c}\text { Age (years) } \\
\leq 3 \\
4-11 \\
\geq 12\end{array}$ & $\begin{array}{c}1.0 \\
1.54(0.80-2.97) \\
0.35(0.09-1.30)\end{array}$ & $\begin{array}{c}1.0 \\
3.61(1.90-6.84) \\
4.90(2.30-10.45)\end{array}$ & $<0.001$ \\
\hline $\begin{array}{c}\text { Born in Belgium } \\
\text { Yes } \\
\text { No }\end{array}$ & $\begin{array}{c}1.0 \\
0.93(0.35-2.46)\end{array}$ & $\begin{array}{c}1.0 \\
2.36(1.20-4.64)\end{array}$ & $<0.001$ \\
\hline $\begin{array}{c}\text { Living environment } \\
\text { Family } \\
\text { Other }\end{array}$ & $\begin{array}{c}1.0 \\
0.79(0.28-2.21)\end{array}$ & $\begin{array}{c}1.0 \\
0.12(0.03-0.58)\end{array}$ & 0.009 \\
\hline $\begin{array}{c}\text { Admission } \\
\text { Emergency } \\
\text { Planned or transfer }\end{array}$ & $\begin{array}{c}1.0 \\
0.44(0.19-1.07)\end{array}$ & $\begin{array}{c}1.0 \\
1.10(0.52-2.31)\end{array}$ & 0.040 \\
\hline $\begin{array}{c}\text { Knownprevious case files } \\
\text { Yes } \\
\text { No }\end{array}$ & $\begin{array}{c}1.0 \\
1.92(1.04-3.53)\end{array}$ & $\begin{array}{c}1.0 \\
0.57(0.33-0.99)\end{array}$ & 0.007 \\
\hline
\end{tabular}

prevention. So, as postulated by the World Health Organization [2] and by McKenzie [10] [11] and colleagues, population-based surveys are essential element for determining the true extent of non-fatal child abuse but hospital data are also necessary in an integrated data surveillance system.

\section{References}

[1] World Health Organization and International Society for Prevention of Child Abuse and Neglect (2006) Preventing Child Maltreatment: A Guide to Taking Action and Generating Evidence. The World Health Organization, Geneva. http://www.who.int/violence_injury_prevention/publications/violence/child_maltreatment/en

[2] World Health Organization (2002) World Report on Violence and Health. The World Health Organization, Geneva. http://www.who.int/violence_injury_prevention/violence/world_report/en

[3] Black, D.A., Heyman, R.E. and Smith Slep, A.M. (2001) Risk Factors for Child Physical Abuse. Aggression and Violent Behavior, 6, 121-188. http://dx.doi.org/10.1016/S1359-1789(00)00021-5

[4] Black, D.A., Smith Slep, A.M. and Heyman, R.E. (2001) Risk Factors for Child Psychological Abuse. Aggression and Violent Behavior, 6, 189-201. http://dx.doi.org/10.1016/S1359-1789(00)00022-7

[5] Black, D.A., Heyman, R.E. and Smith Slep, A.M. (2001) Risk Factors for Child Sexual Abuse. Aggression and Violent Behavior, 6, 203-229. http://dx.doi.org/10.1016/S1359-1789(00)00023-9

[6] Gilbert, R., Spatz Widom, C., Browne, K., Ferguson, D., Webb, E. and Janson, S. (2009) Burden and Consequences of Child Maltreatment in High-Income Countries. The Lancet, 373, 68-81. http://dx.doi.org/10.1016/S0140-6736(08)61706-7

[7] Schumacher, J.A., Smith Slep, A.M. and Heyman, R.E. (2001) Risk Factors for Child Neglect. Aggression and Violent Behavior, 6, 231-254. http://dx.doi.org/10.1016/S1359-1789(00)00024-0

[8] Rao, S. and Lux, A.L. (2012) The Epidemiology of Child Maltreatment. Paediatrics and Child Health, 22, $459-464$. http://dx.doi.org/10.1016/j.paed.2012.09.002

[9] Fallon, B., Trocmé, N., Fluke, J., MacLaurin, B., Tonmyr, L. and Yuan, Y. (2010) Methodological Challenges in Measuring Child Maltreatment. Child Abuse \& Neglect, 34, 70-79. http://dx.doi.org/10.1016/j.chiabu.2009.08.008

[10] McKenzie, K. and Scott, D.A. (2011) Using Routinely Collected Hospital Data for Child Maltreatment Surveillance: Issues, Methods and Patterns. BMC Public Health, 11, 7. 
[11] McKenzie, K., Scott, D.A., Waller, G.S. and Campbell, M. (2011) Reliability of Routinely Collected Hospital Data for Child Maltreatment Surveillance. BMC Public Health, 11, 8. http://dx.doi.org/10.1186/1471-2458-11-8

[12] AlEissa, M.A., Fluke, J.D., Gerbaka, B., Goldbeck, L., Gray, J., Hunter, N., Madrid, B., Van Puyenbroeck, B., Richards, I. and Tonmyr, L. (2009) A Commentary on National Child Maltreatment Surveillance Systems: Examples of Progress. Child Abuse \& Neglect, 33, 809-814. http://dx.doi.org/10.1016/j.chiabu.2009.08.004

[13] Fagerland, M.W. and Hosmer, D.W. (2012) A Generalized Hosmer Lemeshow Goodness-of-Fit Test for Multinomial Logistic Regression Models. Stata Journal, 12, 447-453.

[14] Chen, W., Glasser, S., Benbenishty, R., Davidson-Arad, B., Tzur, S. and Lerner-Geva, L. (2010) The Contribution of a Hospital Child Protection Team in Determining Suspected Child Abuse and Neglect: Analysis of Referrals of Children Aged 0 - 9. Children and Youth Services Review, 32, 164-1669.

[15] Glaser, D. (2005) Child Maltreatment. Psychiatry, 4, 53-57. http://dx.doi.org/10.1383/psyt.2005.4.7.53

[16] Keshavarz, R., Kawashima, R. and Low, C. (2002) Child Abuse and Neglect Presentations to a Pediatric Emergency Department. The Journal of Emergency Medicine, 23, 341-345. http://dx.doi.org/10.1016/S0736-4679(02)00575-9

[17] Australian Institute of Family Studies (2013) Risk and Protective Factors for Child Abuse and Neglect. The Institute, Melbourne. http://www.aifs.gov.au/cfca/pubs/factsheets/a143921/

[18] Stith, S.M., Liu, T., Davies, C., Boykin, E.L, Alder, M.C., Harris, J.M., Som, A., McPherson, M. and Dees, J.EM.E.G. (2009) Risk Factors in Child Maltreatment: A Meta-Analytic Review of the Literature.

[19] Barudy, J., Crappe, J.Y. and Marquebreucq, A.P. (2001) Support the Welfare of Families in Exile. Thérapie Familiale, 22, 153-168. (in French) http://dx.doi.org/10.3917/tf.012.0153 
Scientific Research Publishing (SCIRP) is one of the largest Open Access journal publishers. It is currently publishing more than 200 open access, online, peer-reviewed journals covering a wide range of academic disciplines. SCIRP serves the worldwide academic communities and contributes to the progress and application of science with its publication.

Other selected journals from SCIRP are listed as below. Submit your manuscript to us via either submit@scirp.org or Online Submission Portal.
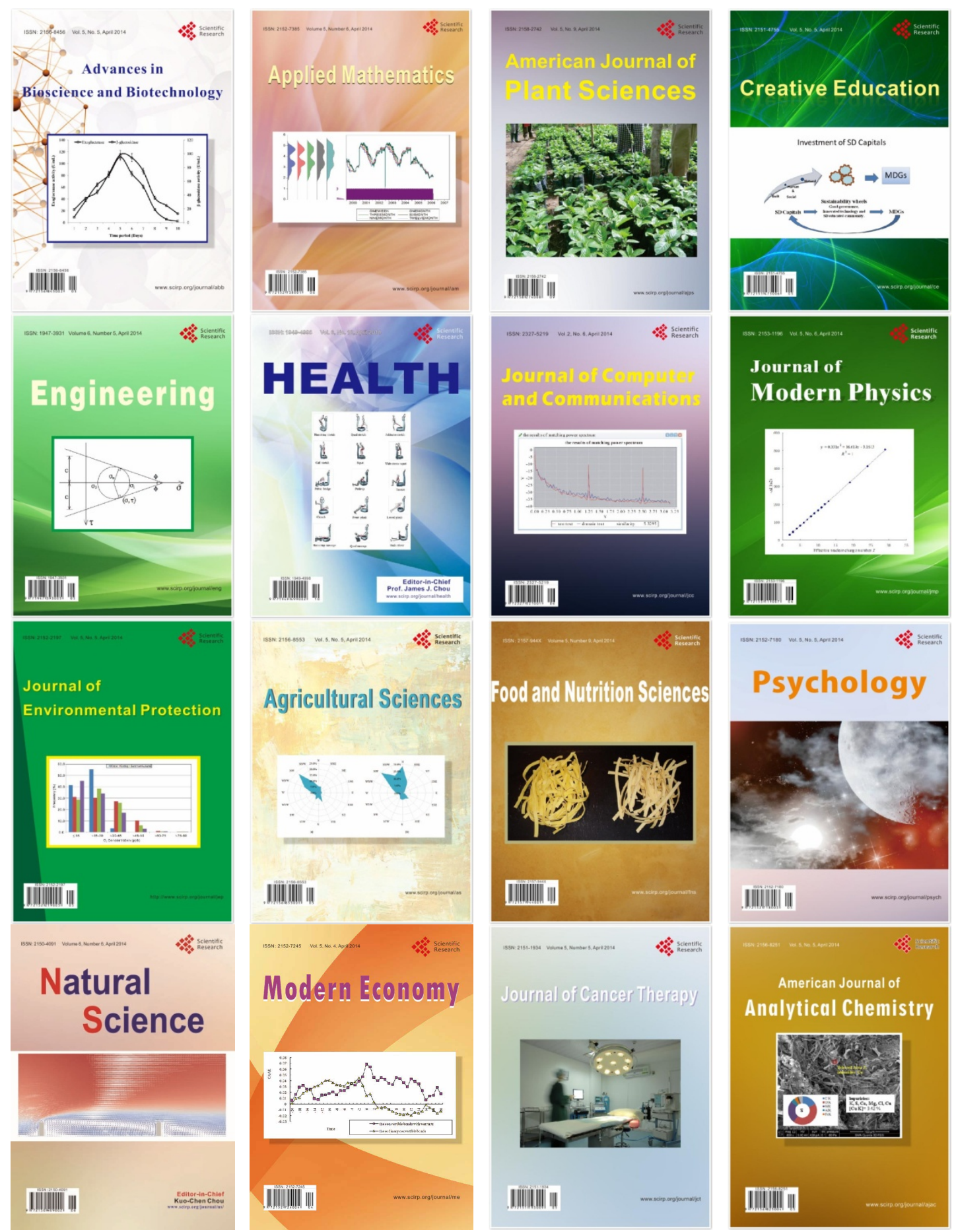